\title{
Quantifying Potential Cost-Savings Through an Alternative Imaging-Based Diagnostic Process in Presumptive Seronegative Rheumatoid Arthritis
}

\author{
Pedro Santos-Moreno (iD) \\ Nelson J Alvis-Zakzuk (D) ${ }^{2}$ \\ Edwin Castillo' \\ Laura Villarreal' \\ Carlos Pineda $\mathbb{D}^{3}$ \\ Hugo Sandoval (1D ${ }^{4}$ \\ Omaira Valencia (1D) ${ }^{1,5}$ \\ 'Center of Rheumatoid Arthritis, \\ BIOMAB, Bogota, Colombia; \\ ${ }^{2}$ Universidad de la Costa-CUC, \\ Departamento de Ciencias Económicas, \\ Barranquilla, Colombia; ${ }^{3}$ Sociomedical \\ Research Unit, Instituto Nacional de \\ Rehabilitación Luis Guillermo Ibarra \\ Ibarra, Ciudad de México, Mexico; \\ ${ }^{4}$ Sociomedical Research Unit, Instituto \\ Nacional de Rehabilitación Luis \\ Guillermo Ibarra Ibarra, Ciudad de \\ México, México; ${ }^{5}$ Fundación Santa Fé de \\ Bogotá, Bogotá, Colombia
}

Background: Seronegative rheumatoid arthritis (SRA) is a condition that is not well understood and difficult to confirm by a conventional diagnostic process. We aimed to quantify the potential cost-savings of an alternative diagnostic process (ADP) imagingbased, for patients with presumptive SRA from everyday clinical practice.

Methods: We performed a retrospective analysis for patients with presumptive SRA who tested negative for both rheumatoid factor and anti-cyclic citrullinated peptide antibodies, through an ADP imaging-based, that is a standard clinical practice in our center. After we confirmed the diagnosis of SRA or reclassified patients in terms of another proper diagnosis, we estimate direct costs in two scenarios: a conventional and ADP. We compared the cost of RA treatment during the first year against the cost of the most misdiagnosed treatment (osteoarthritis) found after applying the ADP to determine potential cost-savings.

Results: We included 440 patients with a presumptive diagnosis of SRA. According to the imaging-based ADP, SRA was confirmed in 106/440 (24.1\%), unspecified RA in 9/440 $(2.0 \%)$, and osteoarthritis in $325 / 440(73.9 \%)$ of those patients. Although the costs of conventional diagnosis per patient is lower than those of ADP $(\$ 59,20$ USD vs $\$ 269,57$ USD), we found a potential drug cost-savings of $\$ 1,570,775.20$ US Dollars after 1 year of correct treatment.

Conclusion: An alternative diagnosis process, including X-rays, US and MRI imaging, and clinical and blood-test assessment, not only increased diagnostic certainty in patients referred for evaluation of presumptive SRA but also suggested a potential cost-savings in pharmacological treatments avoided in misdiagnosed patients.

Keywords: cost-savings, seronegative rheumatoid arthritis, diagnosis, imaging

\section{Background}

The 2010 Rheumatoid Arthritis (RA) classification criteria of the American College of Rheumatology (ACR) and the European League Against Rheumatism (EULAR) are based on clinical (joint involvement and duration of symptoms), serologic, and acute-phase reactant domains, allowing the identification of patients at early disease stages who may benefit from the institution of early treatment. ${ }^{1}$

Because serological status is of paramount importance for the diagnosis, prognosis, and treatment of RA, ${ }^{2}$ we classified it as seropositive (ICD-10 code M059) or seronegative (ICD-10 code M060) in terms of the seropositivity - or seronegative — of rheumatoid factor (RF) and anti-cyclic citrullinated peptide antibodies (ACPA).
Correspondence: Omaira Valencia Fundación Santa Fé de Bogotá, Carrera 7B \# 123-90, Bogotá, Colombia Email o.valencial0@uniandes.edu.co 
Seronegative RA (SRA) is a condition that is not well understood and difficult to confirm by a conventional diagnostic process, with high probabilities of its being confused with other inflammatory arthropathies ${ }^{3,4}$ and requiring a consultation with an expert rheumatologist. Misdiagnosis of SRA could be more frequent in patients in whom presumptive SRA is seronegative for both RF and ACPA, but still be positive for clinical domains.

Although radiography (X-ray) is the gold standard for imaging in RA, this tool is insensitive for detecting bone erosions or inflammatory changes within the joint tissues during the earliest stages of the disease process. ${ }^{3,5}$

Several studies have shown that magnetic resonance imaging (MRI) is a sensitive and reproducible imaging tool for the diagnosis, follow-up, and assessment of both the inflammatory activity and the structural damage of the disease, and for the prognosis of patients with RA. This advanced imaging technology permits direct visualization of the anatomical structures that may be involved in the disease's inflammatory process from its earliest stages. ${ }^{6}$

In the same way, ultrasound (US) allows an accurate evaluation of RA elementary lesions such as synovitis, tenosynovitis, and erosions, with direct visualization of early inflammatory and destructive joint changes. ${ }^{3,5,7}$ Both imaging techniques (MRI and US) are efficient methods for the diagnosis, monitoring, and prognostication of early RA, avoiding the potential costs from unnecessary treatments deriving from misdiagnosis. ${ }^{8}$

For some time, in our center, we had observed that there is a high percentage of patients with osteoarthritis but with a diagnosis of seronegative RA; we believe that it is because the ACR/EULAR 2010 classification criteria commonly are used for guiding the diagnosis and the criteria have a weakness: you do not need RF or ACPA to make the diagnosis; using the clinical domain, a high ESR/CRP and the criterion of time, you can "make" the diagnosis; on the other hand, negative RF and ACPA do not give "points".

For this reason, in our center we have in last years, defended the position that even having a typical clinical picture of RA, if the patient's RF and anti-CCP are negative, the diagnosis of seronegative RA should be confirmed by imaging, using the conventional X-rays, the magnetic resonance imaging (MRI) and the ultrasound (US).

An alternative diagnostic process (ADP) combining clinical criteria, laboratory tests of RF and ACPA, and imaging techniques as X-rays, MRI and US may be beneficial for improving the early detection and proper diagnosis of RA. According to these considerations, we aimed to evaluate the potential cost-savings related to the misdiagnosis and treatment of presumptive SRA by means of an ADP developed at a specialized in RA center (Center) from a healthcare perspective.

\section{Methods}

We developed a retrospective everyday clinical-practice data analysis from the clinical records of patients with a diagnosis of presumptive seronegative RA who were referred to a specialized Center for the provision of rheumatologic care.

This research did not involve the collection or use of individually identifiable health-related data. All clinical records were de-identified in order to preserve the patient's privacy by assigning an identification number to each subject. Anonymous patient-data inputs were stored and analyzed in line with ethical compliance.

\section{Inclusion and Exclusion Criteria}

We analyzed electronic health records between July 2016 and June 2017, for all patients referred to the Center by their insurance companies or payers with a presumptive diagnosis of seronegative RA. Patients were included if they tested negative for both RF and ACPA biomarkers, but fulfilled the classification criteria of RA according to ACR/EULAR 2010 classification criteria. ${ }^{1}$

We excluded patients without typical clinical symptoms of RA, with a sole serological (RF or ACPA) negative test, patients younger than 18 years of age, those with juvenile-onset idiopathic arthritis, patients with spondyloarthritis, ${ }^{9}$ those with other autoimmune disorders like systemic lupus erythematosus, ${ }^{10}$ Sjogren syndrome, ${ }^{11}$ or those not fulfilling the clinical domains of ACR/ EULAR 2010 classification criteria. ${ }^{1}$

\section{Ethics}

According to Resolution 8430 of 1993 from the Ministry of Health of Colombia, this research presents no risks to patients; therefore, this study does not need approval from the ethics committee. The authors declare to adhere to the Declaration of Helsinki in all aspects of ethics. This study was approved by the Institutional Review Board of BIOMAB IPS, act number 007 of 27 July, 2017 (code GC.IN.01.FR.03). All patients had previously signed informed consent for data use; the database was anonymized to protect the confidentiality and privacy of patients. 


\section{Alternative Diagnostic Process}

Figure 1 describes the ADP algorithm used for confirming diagnosis of seronegative RA. As mentioned a little above, the procedure called alternative diagnostic process (ADP) is a standard practice in our center for several years that has been applied in patients with a presumptive diagnosis of seronegative RA, and it was established to avoid seronegative RA false positives diagnoses. Patients were assessed by at least one imaging technique (US, X-ray, or MRI) according to the specialized Center's ADP process.

First, the patient with symptoms suggestive of RA and who already has a negative RF and ACPA depending on the time of evolution is subjected to imaging; if the disease has more than 2 years of evolution, X-rays of the hands and feet are performed; in case that erosions are observed, the diagnosis of seronegative RA is confirmed, but if there are no erosions or typical chronic changes of RA, the patient undergoes to an US of the hands and feet, which is considered positive for RA if are observed at least two zones of Power Doppler and/or synovitis greater than or equal to grade two; in case of disease evolution less than 2 years, an US was performed without previusly X-ray.

In those patients whose ultrasound is not conclusive, they undergo to MRI, where to confirm the diagnosis of seronegative RA, erosions and/or edema of the bone marrow without/with associated synovitis must be observed.

The Ultrasound (US) scanning protocol included the following bilateral anatomical areas: wrists, 1-5 metacarpophalangeal joints; $1-5$ proximal interphalangeal joints, and 1-5 metatarsophalangeal joints, and the following tendons: 2-6 extensor wrist compartments; $2-5$ digital flexor tendons of the hands, and posterior tibial tendons.

We employed an Esaote MyLab7 ${ }^{\mathrm{TM}}$ (Genoa, Italy) ultrasound scanner equipped with a linear high-frequency (6-18 MHz) transducer. Gray-scale synovitis was defined according to OMERACT recommendations. ${ }^{12,13}$ For each synovial recess, B-mode synovitis and power Doppler were quantified utilizing a semi-quantitative scale according to Szkudlarek et al. ${ }^{14}$

According to the specialized Center ADP algorithm, MRI was performed in patients whose US examination showed power Doppler grade 1 or gray-scale synovitis grade 1 in more than two joints, using a Multiva 1.5T Philips MRI system. OMERACT recommendations of basic MRI sequences and definitions in RA joint pathologies were employed. ${ }^{6}$ We did not use gadolinium contrast enhancement. Magnetic resonance (MR) images were read by a Radiologist trained in RAMRIS-Scoring, who was blinded to clinical data. Images were evaluated for synovitis, bone-marrow edema, and erosions, according to OMERACT 2016 RAMRIS. ${ }^{6}$

Clinical classification of patients as seronegative RA, osteoarthritis, or another proper diagnosis, was performed combining the clinical criteria with the results of the imaging studies, as depicted in Figure 1.

\section{Cost-Analysis of Diagnosis and Treatment}

In this study, we assumed that misdiagnosed patients with seronegative RA may experience a higher cost of medical care, generated through the implementation of comprehensive medical care, including unnecessary laboratory tests, specialist's follow-up visits, treatments, and their potential adverse effects. To compare the misdiagnosis and correct diagnosis of seronegative RA, we estimated direct medical costs for diagnosis and treatment according to the disease. We performed a cost-analysis in two scenarios:

1. Conventional RA diagnosis. This scenario reflects, as closely as possible, the current recommendations for the diagnosis and treatment of RA. ${ }^{1}$ Also, it describes the cost-of-illness for a patient with presumptive RA diagnosed through a consultation with a Rheumatologist and laboratory tests, including RF and ACPA acute-phase reactants (erythrocyte sedimentation rate) and $\mathrm{x}$-rays of hands and feet. We also included pharmacologic treatment (conventional and biologic DMARD), glucocorticoids, NSAID, and analgesics. Here, we assumed that all patients were diagnosed and treated as having RA.

2. Alternative RA diagnosis process: In this scenario, patients with presumptive RA are screened through the specialized Center ADP algorithm depicted in Figure 1. We performed the diagnosis through consultations with a Rheumatologist, laboratory test (RF, ACPA, and erythrocyte sedimentation rate) determinations, hands and feet x-rays, US, and MRI. This ADP algorithm may potentially increase diagnostic accuracy, thus minimizing false positives diagnosis of RA.

In this latter scenario, not all patients were diagnosed with seronegative RA: a proportion of the patients were diagnosed with OA or had an alternative diagnosis. To describe the potential cost-savings due to the implementation of the 


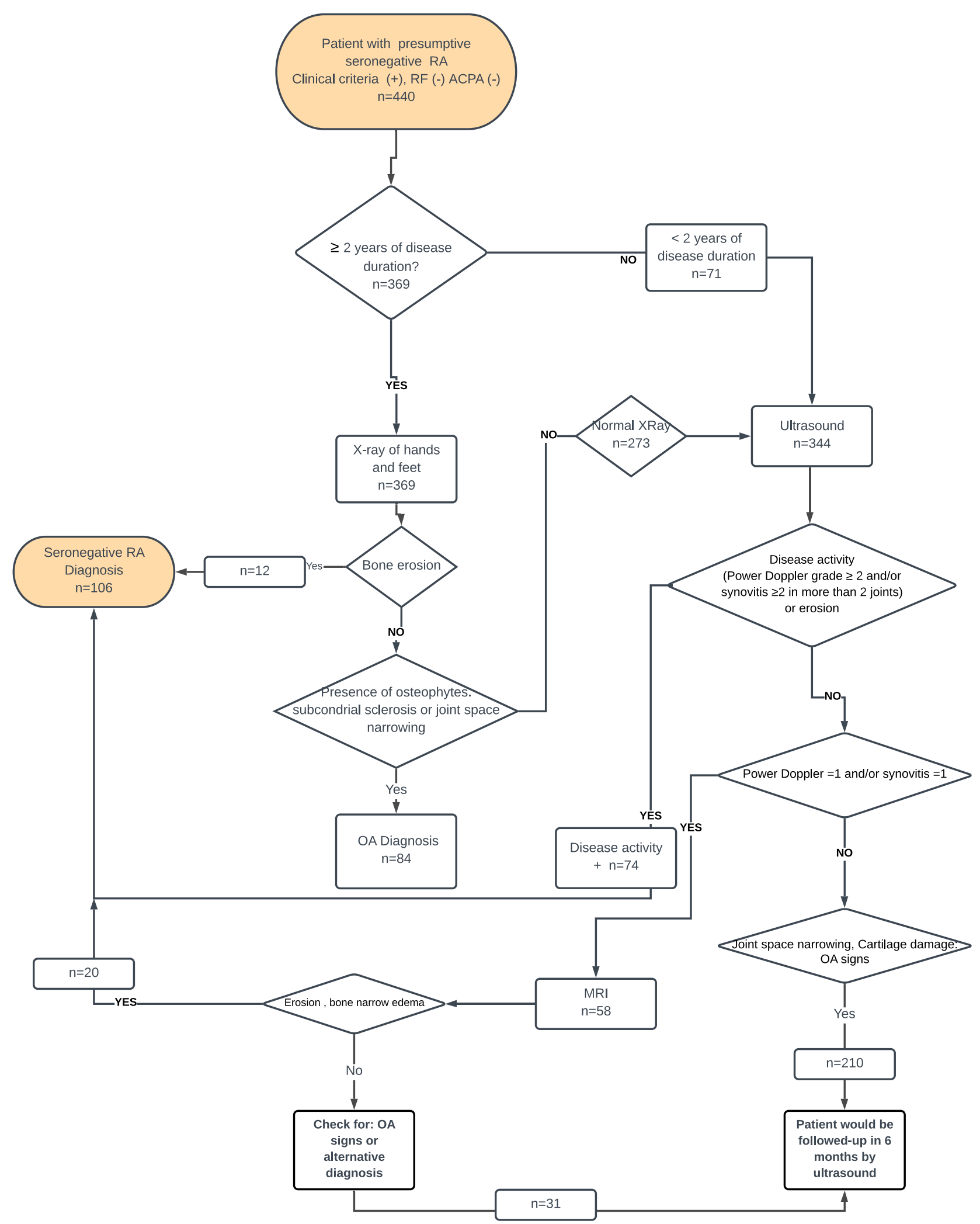

Figure I Alternative Diagnosis process (ADP): Diagram describing the diagnosis and the number of patients according to the point-in-process classification. 
specialized Center ADP algorithm, direct medical costs based on consultations with Medical Specialists, pharmaceutical treatment, and laboratory and imaging tests during the first year of treatment were estimated based on ACR and EULAR recommendations for RA and OA. ${ }^{15-18}$

Direct medical costs were estimated using the recommendations and guidelines from the Manual for the Preparation of Economic Evaluations in Health, published by the Institute of Technological Evaluation in Health (IETS), ${ }^{19}$ the official agency for health technology assessment in Colombia. We also followed Consolidated Health Economic Evaluation Reporting Standards (CHEERS) statements for accurate reporting in the health economic evaluation. ${ }^{20}$

We estimated the costs of pharmacological treatments from tariffs reported from: a) Circulars of the National Commission of the prices of medicines and medical devices, which set maximal prices for some drugs in Colombia, and b) The Price Information System of Medicines (SISMED, the official source of the prices of drugs and sales-volume information. ${ }^{21}$

Because the unit value and market share of drugs for RA and OA were both known, we estimated a weighted mean cost, with its minimal and maximal costs. The costs of laboratory and imaging tests were processed from national prices, ie, Instituto de Seguros Sociales 2001 plus $30 \%$, as recommended by IETS. ${ }^{19}$

\section{Statistical Analysis}

A descriptive analysis of the characteristics of patients and classification of diagnosis was developed using STATA V13 software. In addition, data from medical costs were collected and analyzed in Microsoft Excel 365. To report results, mean, minimal and maximal (Min-Max) costs per patient were estimated. All costs were expressed in 2017 prices and were converted into US dollars (USD), using the mean exchange rate from $01 / 01 / 2017$ to $12 / 31 / 2017$, where $1 \mathrm{USD}=\$ 2,951.30$ Colombian pesos $(\mathrm{COP})$.

\section{Results}

\section{Patients' Characteristics}

A total of 440 patients with a mean age of 58 years (Standard deviation $[\mathrm{SD}] \pm 12.3$ years) were included in the analysis; of these, 356/440 (80.1\%) were female. The proportion of patients with more than 2 years since the onset of a joint symptom was 368/440 (83.6\%). According to the specialized Center's ADP algorithm, we assessed
$369 / 440(83.9 \%)$ patients by $x-r a y, 344 / 440(78.1 \%)$ by US, and 58/440 (13.1\%) by MRI.

\section{Imaging Assessment}

X-ray assessment showed that 12/369 (3.3\%) patients had bone erosion consistent with a diagnosis of seronegative RA. Nineteen percent were positive for OA changes (asymmetric joint-space narrowing, osteophyte formation, subchondral sclerosis), while the remaining 273/369 (62.3\%) evidenced no joint abnormalities (normal x-rays). We assessed by US the following patients: 1) those with normal results by $x$-ray, and 2) those with fewer than 2 years of disease duration since the onset of symptoms.

As revealed in Figure 1, US assessment demonstrated that $74 / 344(21.5 \%)$ patients had elementary inflammatory lesions (gray-scale synovitis and power Doppler signals) or structural changes (erosions), suggesting the presence of seronegative RA, while $1.7 \%$ exhibited normal US results and 210/344 (61\%) displayed changes compatible with a diagnosis of OA.

We classified the US findings as inconclusive in 58/344 $(16.8 \%)$ patients (power Doppler $=1$ or grey-scale synovitis $=1$, according to Figure 1). MRI evaluation permitted us to reclassify $20 / 58$ patients $(34.4 \%)$ with erosions or subchondral bone-marrow edema as seronegative RA, whereas $31 / 58$ (53.4\%) were positive for OA changes. The remaining $7 / 58$ (12\%) patients showed no MRI abnormalities.

\section{Final Diagnosis}

According to the International Classification of Diseases 10th Revision (ICD-10 classification), at the end of the ADP algorithm, we diagnosed 106/440 (24.1\%) patients as having seronegative RA. We classified the remaining 9/ 440 patients $(2.0 \%)$ as having unspecified arthritis and $325 / 440(73.9 \%)$ as having OA.

We identified the patients classified as seronegative RA as follows: 13/106 (12.3\%) patients by x-ray; 72/106 (67.9\%) patients by US, and the remaining 21/106 (19.8\%) patients by MRI. After applying the ADP, OA was the most frequent misdiagnosis with 206/325 (63.4\%) of these cases identified by US.

\section{Cost of Diagnosis and Treatment}

Table 1 presents the direct medical cost related to the diagnosis of RA. The conventional total diagnostic cost was estimated at $\$ 59.20$ USD (of which $27 \%$ was due to 
Table I Direct Costs Related to Diagnosis of Presumptive Seronegative RA

\begin{tabular}{|c|c|c|c|c|}
\hline \multirow[t]{2}{*}{$\begin{array}{l}\text { Type of Diagnostic } \\
\text { Tool }\end{array}$} & \multicolumn{2}{|c|}{$\begin{array}{c}\text { Conventional } \\
\text { Diagnosis }\end{array}$} & \multicolumn{2}{|c|}{$\begin{array}{l}\text { Screening } \\
\text { Diagnosis }\end{array}$} \\
\hline & Freq. & $\begin{array}{l}\text { Cost } \\
\text { (USD) }\end{array}$ & Freq. & $\begin{array}{l}\text { Cost } \\
\text { (USD) }\end{array}$ \\
\hline $\begin{array}{l}\text { Reumathology } \\
\text { consultation }\end{array}$ & 2 & $\$ 16.11$ & 3 & $\$ 24.05$ \\
\hline Rheumatoid factor test & I & $\$ 14.58$ & 1 & $\$ 14.58$ \\
\hline ACPA test & I & $\$ 13.71$ & I & $\$ 13.7 \mid$ \\
\hline Sedimentation rate & I & $\$ 0.65$ & I & $\$ 0.65$ \\
\hline Foot X-Ray & I & $\$ 7.07$ & I & $\$ 7.07$ \\
\hline Hand X-Ray & 1 & $\$ 7.07$ & I & $\$ 7.07$ \\
\hline Ultrasound & & $* *$ & I & $\$ 26.99$ \\
\hline$M R I^{*}$ & & $* *$ & I & $\$ 175.43$ \\
\hline Total & & $\$ 59.20$ & & $\$ 269.57$ \\
\hline
\end{tabular}

Notes: * Cost not applied; *MRI was required in 13\% of patients; This table describes the cost by the conventional diagnosis and the cost using the ADP. Abbreviations: ACPA, Anti-cyclic citrullinated peptide antibodies; MRI, Magnetic resonance imaging.

consultations with the Rheumatologist). The cost of the alternative diagnosis process was \$269.57 USD. The largest share of this cost was related to the use of imaging techniques, including x-rays, US, and MRI (65.2\%).

Table 2 shows that the estimated mean cost per seronegative RA patient for 1 year of follow-up was $\$ 5,419.3$ USD (range, \$5,125.8 USD-\$5,787.7 USD), while Table 3 presents the mean cost for OA as $\$ 526.3$ USD (range, \$394.5 USD-\$867.5 USD). The highest cost in seronegative RA was related to the pharmacological treatment, accounting for $\$ 5,332.6$ USD (98.4\% of the total cost; see Table 2). For OA, the proportion of pharmacological treatment in the total cost of the treatment per year was $92.2 \%$.

We calculated the cost of biologic therapy $(\$ 4,211.0$ USD per year; see Table 2) assuming that these biodrugs were included in month 6 of treatment -after conventional DMARD therapy failure- representing the highest cost of pharmaceutical therapy.

Assuming patients with seronegative RA without biologic therapy, the cost of treatment continued to be higher than that of OA. According to Table 2, we estimated the cost per year with DMARD therapy as \$1,123.6 USD (sum of monotherapy, combined therapy, glucocorticoids, and analgesics) compared with that of OA, with a cost of \$526.3 USD

\section{Potential Cost-Savings}

Table 4 depicts the comparison of the two cost scenarios. The cost per patient in the conventional scenario (which includes \$59.20 USD for common diagnosis and $\$ 5,419.13$ USD for RA treatment per year) was $\$ 5,478.33$ USD. In this manner, treating 440 patients with presumptive seronegative RA would represent an economic burden of $\$ 2,384,474.2$ USD for the third payer. The alternative diagnostic-process scenario estimated an ADP of \$269.6 USD plus \$5,419.3 USD of a cost per patient for RA treatment, totaling $\$ 5,715.9$ USD for seronegative RA and \$296.6 USD plus \$526.3 USD (for a total of $\$ 822.9$ USD) for OA, respectively.

In this scenario, we confirmed 106 patients with seronegative RA and 325 patients with OA. The total economic burden per year, assuming the treatment in the 431 patients in this scenario, was $\$ 839,748.5$ USD. In this manner, we found a potential cost-savings by using the ADP algorithm of $\$ 1,570,775.2$ USD per year (Table 4).

\section{Discussion}

This study showed how an ADP algorithm that combines imaging and laboratory tests, along with clinical criteria, could introduce potential savings in the costs of medical care from the perspective of the third payer.

Some studies suggest that the two serotypes of RA seronegative and seropositive- may reflect different entities. Despite their clinical overlap, they differ in terms of genetic basis, immunopathology, differential diagnosis, treatment, and even patient outcome; therefore, proper differentiation from the early disease stages is of utmost importance. ${ }^{1,3}$

Our results, based on everyday clinical-practice evidence from a single Center, also demonstrated how the use of imaging techniques improves the accuracy of the diagnosis of double-seronegative RA and identifies other sources of joint damage that indicate alternative differential diagnoses. Thus, an alternative imaging-based diagnostic process could assist in the evaluation of the Rheumatologist in cases where RA serologic biomarkers are negative despite the presence of clinical criteria, enabling the diagnosis of seronegative RA, or suggesting an alternative diagnosis, such as OA.

Evaluating the costs of diagnostic interventions and medical treatments is important, but is often a difficult task. Cost estimates related to medical care must include not only the costs of diagnostic tests (laboratory and 
Table 2 Estimation of Direct Cost of RA Treatment* in the First Year After Diagnosis per Patient

\begin{tabular}{|c|c|c|c|c|c|}
\hline \multirow[t]{4}{*}{ Activity } & \multicolumn{5}{|c|}{ MDA-HDA** } \\
\hline & \multicolumn{5}{|c|}{ Cost (USD) } \\
\hline & 3 Months & 3-6 Months & 6-9 Months & 9-12 Months & Total per Year \\
\hline & Mean (Min-Max) & Mean (Min-Max) & Mean (Min-Max) & Mean (Min-Max) & Mean (Min-Max) \\
\hline \multicolumn{6}{|c|}{ Pharmacological treatment } \\
\hline $\begin{array}{l}\text { Monotherapy } \\
\text { MTX }\end{array}$ & $\$ 464.8(464.6-473.9)$ & & & & $\$ 464.8(464.6-473.9)$ \\
\hline $\begin{array}{l}\text { Combined therapy } \\
\text { MTX } \\
\text { SSZ } \\
\text { HCQ }\end{array}$ & & $\begin{array}{r}\$ 464.8(464.6-473.9) \\
\$ 12.5(10.6-17.2) \\
\$ 113.1(100.7-179.2)\end{array}$ & & & $\begin{array}{c}\$ 464.8(464.6-473.9) \\
\$ 12.5(10.6-17.2) \\
\$ 113.1(100.7-179.2)\end{array}$ \\
\hline $\begin{array}{c}\text { Biologic } \\
\text { TNFi }\end{array}$ & & & $\begin{array}{r}\$ 2,105.5 \\
(1,978.1-2,205.6)\end{array}$ & $\begin{array}{r}\$ 2,105.5 \\
(I, 978.1-2,205.6)\end{array}$ & $\begin{array}{c}\$ 4,2 \mid I .0 \\
(3,956.3-4,4 \mid I .2)\end{array}$ \\
\hline $\begin{array}{l}\text { Glucorticoid } \\
\text { Prednisone } \\
\text { Folic Acid }\end{array}$ & $\begin{array}{l}\$ 2.7(2.6-4.4) \\
\$ 0.6(0.6-1.2)\end{array}$ & $\begin{array}{l}\$ 2.7(2.6-4.4) \\
\$ 0.6(0.6-1.2)\end{array}$ & $\$ 0.6(0.6-1.2)$ & $\$ 0.6(0.6-1.2)$ & $\begin{array}{l}\$ 5.4(5.3-8.8) \\
\$ 2.6(2.2-4.9)\end{array}$ \\
\hline $\begin{array}{l}\text { Analgesics } \\
\text { Acetaminophen }\end{array}$ & $\$ 15.1(9.2-33.5)$ & $\$ 15.1(9.2-33.5)$ & $\$ 15.1(9.2-33.5)$ & $\$ 15.1(9.2-33.5)$ & $\$ 60.4(36.9-133.9)$ \\
\hline $\begin{array}{l}\text { Laboratory } \\
\text { Complete blood count } \\
\text { Transaminases } \\
\text { Creatinine } \\
\text { TB }\end{array}$ & $\begin{array}{l}\$ 4.9(4.9-4.9) \\
\$ 6.2(6.2-6.2) \\
\$ 1.5(1.5-1.5)\end{array}$ & $\begin{array}{l}\$ 4.9(4.9-4.9) \\
\$ 6.2(6.2-6.2) \\
\$ 1.5(1.5-1.5)\end{array}$ & $\begin{array}{l}\$ 4.9(4.9-4.9) \\
\$ 6.2(6.2-6.2) \\
\$ 1.5(1.5-1.5) \\
\$ 2.2(2.2-2.2)\end{array}$ & $\begin{array}{l}\$ 4.9(4.9-4.9) \\
\$ 6.2(6.2-6.2) \\
\$ 1.5(1.5-1.5)\end{array}$ & $\begin{array}{c}\$ 19.7(19.7-19.7) \\
\$ 24.7(24.7-24.7) \\
\$ 5.9(5.9-5.9) \\
\$ 2.2(2.2-2.2)\end{array}$ \\
\hline $\begin{array}{l}\text { Consultation } \\
\text { Rheumatologist }\end{array}$ & $\$ 8.0(8.0-8.0)$ & $\$ 8.0(8.0-8.0)$ & $\$ 8.0(8.0-8.0)$ & $\$ 8.0(8.0-8.0)$ & $\$ 32.0(32.0-32.0)$ \\
\hline Total & $\begin{array}{r}\$ 503.9 \\
(497.6-533.6)\end{array}$ & $\begin{array}{r}\$ 629.5 \\
(608.9-730.1)\end{array}$ & $\begin{array}{r}\$ 2,144.1 \\
(2,010.7-2,263.1)\end{array}$ & $\begin{array}{r}\$ 2,141.8 \\
(2,008.5-2,260.9)\end{array}$ & $\begin{array}{r}\$ 5,419.3 \\
(5, \mid 25.8-5,787.7)\end{array}$ \\
\hline
\end{tabular}

Notes: *Standard treatment based on treat to target strategy; **MDA-HAD, Moderate and High Disease Activity; This table shows the cost related to the drug treatment of a patient with RA, according to the scheme proposed by the ACR guideline for the treatment of patients living with RA.

imaging), but also the costs of the clinical follow-up and pharmacological management resulting from the diagnosis based on the test results. ${ }^{22}$ These subsequent costs are often considerably higher than the initial diagnostic costs of a comprehensive evaluation, especially if they include biological therapy or high-cost drugs.

The effective use of diagnostic imaging technologies in guidelines and recommendations often confers no or solely low-level evidence for their cost-effectiveness. Our findings are consistent with previous studies demonstrating that the use of US in the diagnosis process increases diagnostic certainty for inflammatory arthritis and RA. ${ }^{23,24}$ Furthermore, EULAR recommendations for the use of imaging in RA also suggest the use of MRI or US in cases of diagnostic doubt, instead of that of clinical criteria alone (recommendation 1). ${ }^{25}$ Another study evidenced how the use of US could be useful to detect bone erosion suggestive of RA and to detect differences with other joint pathologies resulting in bone erosions, ${ }^{26}$ thus facilitating differential diagnosis.

According to these results, even when the majority of the patients included had undergone more than 2 years of disease duration from the beginning of bone erosions; only $12 \%$ of patients had seronegative RA. On the other hand, a study on radiographic damage analyzing 250 patients with seronegative RA and 
Table 3 Estimation of Direct Cost of OA Treatment in the First Year After Diagnosis per Patient*

\begin{tabular}{|c|c|c|c|c|}
\hline \multirow[t]{3}{*}{ Activity } & \multirow[t]{3}{*}{ Dosage } & \multicolumn{3}{|c|}{ Cost (USD) } \\
\hline & & Moderate Pain & Severe Pain & Mean Cost per Year (USD) \\
\hline & & Mean (Min-Max) & Mean (Min-Max) & Mean (Min-Max) \\
\hline \multicolumn{5}{|l|}{ Pharmacological treatment } \\
\hline Glucosamine/chondroitin sulfate & $1500 \mathrm{mg} / 1200 \mathrm{mg} /$ day & $\$ 80.5(69.5-116.6)$ & $\$ 80.5(69.5-116.6)$ & $\$ 80.5(69.5-116.6)$ \\
\hline Acetaminophen & $3000 \mathrm{mg} /$ day & $\$ 60.4(36.9-133.9)$ & $\$ 60.4(36.9-133.9)$ & $\$ 60.4(36.9-133.9)$ \\
\hline Tramadol & $10 / 100 \mathrm{mg} /$ day & & $\$ 5.4(3.4-9.8)$ & $\$ 5.4(3.4-9.8)$ \\
\hline Etoricoxib & $90 \mathrm{mg} /$ day & & $\$ 338.8(243.6-566.1)$ & $\$ 338.8(243.6-566.1)$ \\
\hline \multicolumn{5}{|l|}{ Laboratory } \\
\hline Complete blood count & 2 per year & $\$ 9.8(9.8-9.8)$ & $\$ 9.8(9.8-9.8)$ & $\$ 9.8(9.8-9.8)$ \\
\hline Transaminases & 2 per year & $\$ 12.3(12.3-12.3)$ & $\$ 12.3(12.3-12.3)$ & $\$ 12.3(12.3-12.3)$ \\
\hline Creatinine & 2 per year & $\$ 3.0(3.0-3.0)$ & $\$ 3.0(3.0-3.0)$ & $\$ 3.0(3.0-3.0)$ \\
\hline \multicolumn{5}{|l|}{ Consultation } \\
\hline Rheumatologist & 2 per year & $\$ 16.0(16.0-16.0)$ & $\$ 16.0(16.0-16.0)$ & $\$ 16.0(16.0-16.0)$ \\
\hline Total cost per year & & & & $\$ 526.3(394.5-867.5)$ \\
\hline
\end{tabular}

Notes: *Standard treatment based on consensus PANLAR for the treatment of OA. 2016; This table shows the cost associated with the drug treatment of patients with OA.

definite RA demonstrated evidence of major damage in patients with a lengthy disease evolution, with no statistical differences for negative or positive blood biomarkers. ${ }^{27}$

Our study could not confirm the notion that radiography detects a higher proportion of bone erosions in patients with a longer disease duration. An alternative interpretation is that it is difficult to remember precisely the onset of the disease when the latter entertains an insidious type of onset as opposed to the acute onset of symptoms that are more easily recognized by patients. The lag in the detection of RA could also be reduced by training in the wide range of the early symptoms of RA in primary-care medical providers. ${ }^{28}$

Evidence has demonstrated the effectiveness and efficiency of implementing new diagnostic strategies for RA. ${ }^{6,29-35}$ The potential cost-analysis that we performed revealed that applying an ADP algorithm increased the precision of the diagnosis and could represent potential savings of up to $\$ 1.44$ million USD per year to the Colombian health system.

Table 4 Potential Cost-Savings Due to the Application of an Alternative Diagnosis Process

\begin{tabular}{|c|c|c|c|c|}
\hline & & Cost per Patient (USD) & & Cost per Group of Patients (USD) \\
\hline & & Mean (Min-Max) & Freq. & Mean (Min-Max) \\
\hline \multirow{3}{*}{$\begin{array}{l}\text { Conventional RA } \\
\text { diagnosis scenario }\end{array}$} & Conventional diagnosis & $\$ 59.2(59.2-59.2)$ & 440 & $\$ 26,049.5(26,049.5-26,049.5)$ \\
\hline & RA treatment per year & $\$ 5,419.3(5,125.8-5,787.7)$ & 440 & $\$ 2,384,474.2(2,255,352.3-2,546,566.4)$ \\
\hline & Total cost per year & & & $\$ 2.410 .523,8(2.28 I .401,9-2.572 .615,9)$ \\
\hline \multirow{5}{*}{$\begin{array}{l}\text { Alternative RA diagnosis } \\
\text { process scenario }\end{array}$} & ADP* & $\$ 269.6(269.6-269.6)$ & 440 & $\$ 45,492.2(45,492.2-45,492.2)$ \\
\hline & RA treatment per year & $\$ 5,419.3(5,125.8-5,787.7)$ & 106 & $\$ 623,214.9(589,467.1-665,579.8)$ \\
\hline & OA treatment per year & $\$ 526.3(394.5-867.5)$ & 325 & $\$ 17|, 04| .5(|28,198.7-28|, 942.5)$ \\
\hline & Total cost per year & & & $\$ 839,748.5(763,158.0-993,014.5)$ \\
\hline & Cost saving per year & & & $\begin{array}{l}\$ 1,570,775.2 \\
(1,518,243.9-1,579,601.4)\end{array}$ \\
\hline
\end{tabular}

Notes: *440 patients diagnosed with ADP: labs and imaging tests reported at figure 3 (73\% of patients were diagnosed with Ultrasound and I3\% with MRI); This table presents the cost-saving estimation per patient and the group of patients analyzed in the period when the ADP was applied. 
Adding US and MRI to the diagnosis process represented a cost of $\$ 202.42$ USD per patient $(\$ 89,064.8$ USD for the 440 analyzed patients). At first glance, our results imply that diagnostic costs would increase considerably, but this result could be counteracted by the avoided cost resulting from the correct diagnosis and treatment of seronegative RA and OA.

Our study has limitations that must be considered when generalizing its results. The main limitation was related to patients classified as having OA. These patients were not followed up by US to check their disease evolution. However, the majority of these patients continue to be treated at the specialized Center; their follow-up status will be included in a subsequent analysis to verify their outcomes. Another limitation is that we presented only a single-Center experience; therefore, the study lacks control/contrasting data from different centers devoted to the attention of rheumatic diseases. The retrospective design of the study represents an additional limitation. Finally, researchers cannot control exposure or outcome assessment, and instead rely on others for accurate record keeping.

Since our cost comparison comprises an approach of the current RA diagnostic process in Colombia vs one specialized-Center ADP algorithm, the potential cost-savings due to the implementation of this ADP algorithm could not be extrapolated to the entire Colombian health system. It would be interesting to conduct a cost-effectiveness analysis of this strategy to follow a cohort of patients during their lifespan and estimate its potential cost-savings.

The strength of this research lies in that it is based on the everyday clinical practice of a disease management model of care that could improve the diagnostic certainty of seronegative RA, in which US could exert an influence on Rheumatologists in their decisions on making a diagnosis or on re-referring the patient, as shown by Rezaei et al. ${ }^{23}$

\section{Conclusions}

A well-defined process of diagnosis, including imaging, clinical, and blood-test domains significantly increased diagnostic certainty in patients referred for the evaluation of presumptive seronegative RA. Moreover, the use of US and MRI is useful for identifying early damage and synovitis in the diagnosis of seronegative RA and for identifying another proper diagnosis.

This entire process also demonstrates potential pharmacological cost-savings due to the improving certainty in the diagnostic approach, avoiding unnecessary treatments of misdiagnosed patients. Even when the process of diagnosis implies an incremental cost by using imaging, the potential cost-savings in RA pharmacological treatments for patients with another misdiagnosis per year is well above that of the incremental cost of diagnosis; thus, it must be taken into consideration.

\section{Abbreviations}

ACPA, anti-cyclic citrullinated peptide antibodies; RF, rheumatoid factor; MRI, magnetic resonance imaging; ADP, alternative diagnosis process; Center, Center of excellence for rheumatoid arthritis; DMARD, diseasemodifying antirheumatic drug; NSAID, nonsteroidal antiinflammatory drug; US, ultrasound.

\section{Data Sharing Statement}

All data underlying the results are available as part of the article and no additional source data are required.

\section{Author Contributions}

All authors had contributed to the conception, study design, acquisition of data, analysis, interpretation, drafting, critically reviewed, and final approval. All authors have agreed on the journal where is submitted, to take responsibility and be accountable for the contents of the work.

\section{Funding}

No external funding was received for the study.

\section{Disclosure}

Dr Pedro Santos-Moreno reports non-financial support from Abbvie, Bristol, Biopas-UCB, Roche, Sanofi, grants, personal fees from Pfizer, during the conduct of the study. The authors declare that they have no other competing interests.

\section{References}

1. Aletaha D, Neogi T, Silman AJ, et al. 2010 Rheumatoid arthritis classification criteria: an American college of rheumatology/ European league against rheumatism collaborative initiative. Arthritis Rheum. 2010;62(9):2569-2581. doi:10.1002/art.27584

2. Nordberg LB, Lillegraven S, Aga AB, et al. Comparing the disease course of patients with seronegative and seropositive rheumatoid arthritis fulfilling the $2010 \mathrm{ACR} / \mathrm{EULAR}$ classification criteria in a treat-to-target setting: 2-year data from the ARCTIC trial. RMD Open. 2018;4(2):e000752. doi:10.1136/rmdopen-2018-000752

3. Ostergaard M, Pedersen SJ, Dohn UM. Imaging in rheumatoid arthritis- status and recent advances for magnetic resonance imaging, ultrasonography, computed tomography and conventional radiography. Best Pract Res Clin Rheumatol. 2008;22(6):1019-1044. doi:10.1016/j. berh.2008.09.014

4. Pratt AG, Isaacs JD. Seronegative rheumatoid arthritis: pathogenetic and therapeutic aspects. Best Pract Res Clin Rheumatol. 2014;28 (4):651-659. doi:10.1016/j.berh.2014.10.016 
5. Vasanth LC, Pavlov H, Bykerk V. Imaging of rheumatoid arthritis. Rheum Dis Clin North Am. 2013;39(3):547-566. doi:10.1016/j. rdc.2013.03.007

6. Ostergaard M, Peterfy CG, Bird P, et al. The OMERACT rheumatoid arthritis magnetic resonance imaging (MRI) scoring system: updated recommendations by the OMERACT MRI in arthritis working group. $J$ Rheumatol. 2017;44(11):1706-1712. doi:10.3899/jrheum.161433

7. Szkudlarek M, Terslev L, Wakefield RJ, et al. Summary findings of a systematic literature review of the ultrasound assessment of bone erosions in rheumatoid arthritis. J Rheumatol. 2016;43(1):12-21. doi: $10.3899 /$ jrheum. 141416

8. Ostergaard M, Ejbjerg B, Szkudlarek M. Imaging in early rheumatoid arthritis: roles of magnetic resonance imaging, ultrasonography, conventional radiography and computed tomography. Best Pract Res Clin Rheumatol. 2005;19(1):91-116. doi:10.1016/j.berh.2004.08.006

9. Rudwaleit M, van der Heijde D, Landewe R, et al. The development of assessment of spondyloarthritis international society slassification criteria for axial spondyloarthritis (Part II): validation and final selection. Ann Rheum Dis. 2009;68(6):777-783. doi:10.1136/ard.2009.108233

10. Aringer M, Costenbader K, Daikh D, et al. 2019 European league against rheumatism/American college of rheumatology classification criteria for systemic lupus erythematosus. Ann Rheum Dis. 2019;78 (9):1151-1159. doi:10.1136/annrheumdis-2018-214819

11. Shiboski CH, Shiboski SC, Seror R, et al. 2016 American college of rheumatology/European league against rheumatism classification criteria for primary Sjogren's syndrome: a consensus and data-driven methodology involving three international patient cohorts. Ann Rheum Dis. 2017;76 (1):9-16. doi:10.1136/annrheumdis-2016-210571

12. Wakefield RJ, Balint PV, Szkudlarek M, et al. Musculoskeletal ultrasound including definitions for ultrasonographic pathology. J Rheumatol. 2005;32(12):2485-2487.

13. Terslev L, Naredo E, Aegerter P, et al. Scoring ultrasound synovitis in rheumatoid arthritis: a EULAR-OMERACT ultrasound taskforcepart 2: reliability and application to multiple joints of a standardised consensus-based scoring system. RMD Open. 2017;3 (1):e000427. doi:10.1136/rmdopen-2016-000427

14. Szkudlarek M, Court-Payen M, Jacobsen S, Klarlund M, Thomsen HS, Ostergaard M. Interobserver agreement in ultrasonography of the finger and toe joints in rheumatoid arthritis. Arthritis Rheum. 2003;48(4):955-962. doi:10.1002/art.10877

15. England BR, Tiong BK, Bergman MJ, et al. 2019 Update of the American college of rheumatology recommended rheumatoid arthritis disease activity measures. Arthritis Care Res. 2019;71 (12):1540-1555. doi:10.1002/acr.24042

16. Smolen JS, Landewe R, Bijlsma J, et al. EULAR recommendations for the management of rheumatoid arthritis with synthetic and biological disease-modifying antirheumatic drugs: 2016 update. Ann Rheum Dis. 2017;76(6):960-977. doi:10.1136/annrheumdis-2016210715

17. Hochberg MC, Altman RD, April KT, et al. American college of rheumatology 2012 recommendations for the use of nonpharmacologic and pharmacologic therapies in osteoarthritis of the hand, hip, and knee. Arthritis Care Res. 2012;64(4):465-474. doi:10.1002/acr.21596

18. Rausch Osthoff AK, Niedermann K, Braun J, et al. 2018 EULAR recommendations for physical activity in people with inflammatory arthritis and osteoarthritis. Ann Rheum Dis. 2018;77(9):1251-1260. doi:10.1136/annrheumdis-2018-213585

19. Instituto de Evaluación Tecnológica en Salud. Manual para la elaboración de evaluaciones económicas en salud. Bogotá, D.C: IETS; 2014.

20. Husereau D, Drummond M, Petrou S, et al. Consolidated health economic evaluation reporting standards (CHEERS) statement. Int J Technol Assess Health Care. 2013;29(2):117-122. doi: $10.1017 / \mathrm{s} 0266462313000160$
21. Minsalud. SISMED - Sistema de Información de Precios de Medicamentos Ministerio Colombiano de Salud y Protección Social. 2019. Available from: https://www.sispro.gov.co/centralprestadores-de-servicios/Pages/SISMED-Sistema-de-Informacion-dePrecios-de-Medicamentos.aspx. Accessed July 8, 2019.

22. Miles KA. Cancer imaging: is it cost-effective? Cancer Imaging. 2004;4(2):97-103. doi:10.1102/1470-7330.2004.0017

23. Rezaei H, Torp-Pedersen S, Af Klint E, et al. Diagnostic utility of musculoskeletal ultrasound in patients with suspected arthritisa probabilistic approach. Arthritis Res Ther. 2014;16(5):448. doi:10.1186/s13075-014-0448-6

24. Jeka S, Dura M, Zuchowski P, Zwierko B, Waszczak-Jeka M. The role of ultrasonography in the diagnostic criteria for rheumatoid arthritis and monitoring its therapeutic efficacy. Adv Clinical Exp Med. 2018;27(9):1303-1307. doi:10.17219/acem/69133

25. Colebatch AN, Edwards CJ, Ostergaard M, et al. EULAR recommendations for the use of imaging of the joints in the clinical management of rheumatoid arthritis. Ann Rheum Dis. 2013;72 (6):804-814. doi:10.1136/annrheumdis-2012-203158

26. Ventura-Ríos L, Hernández-Díaz C, Sánchez-Bringas G, MadrigalSantillán E, Morales-González JA, Pineda C. A descriptive, cross-sectional study characterizing bone erosions in rheumatoid arthritis and gout by ultrasound. Clin Rheumatol. 2016;35 (9):2269-2276. doi:10.1007/s10067-016-3338-2

27. Sahatciu-Meka V, Rexhepi S, Manxhuka-Kerliu S, Rexhepi M. Radiographic estimation in seropositive and seronegative rheumatoid arthritis. Bosn J Basic Med Sci. 2011;11(3):180-184. doi:10.17305/ bjbms.2011.2571

28. Chan KW, Felson DT, Yood RA, Walker AM. The lag time between onset of symptoms and diagnosis of rheumatoid arthritis. Arthritis Rheum. 1994;37(6):814-820. doi:10.1002/art.1780370606

29. Bird P, Conaghan P, Ejbjerg B, et al. The development of the EULAR-OMERACT rheumatoid arthritis MRI reference image atlas. Ann Rheum Dis. 2005;64(Suppl 1):i8-i10. doi:10.1136/ard.2004.031807

30. Duer-Jensen A, Horslev-Petersen K, Hetland ML, et al. Bone edema on magnetic resonance imaging is an independent predictor of rheumatoid arthritis development in patients with early undifferentiated arthritis. Arthritis Rheum. 2011;63(8):2192-2202. doi:10.1002/art.30396

31. Sugimoto H, Takeda A, Hyodoh K. Early-stage rheumatoid arthritis: prospective study of the effectiveness of MR imaging for diagnosis. Radiology. 2000;216(2):569-575. doi:10.1148/radiology.216.2. r00au20569

32. Nieuwenhuis WP, Krabben A, Stomp W, et al. Evaluation of magnetic resonance imaging-detected tenosynovitis in the hand and wrist in early arthritis. Arthritis Rheumatol. 2015;67(4):869-876. doi:10.1002/art.39000

33. Machado PM, Koevoets R, Bombardier C, van der Heijde DM. The value of magnetic resonance imaging and ultrasound in undifferentiated arthritis: a systematic review. J Rheumatol. 2011;87:31-37. doi:10.3899/jrheum.101072

34. Narváez J, Sirvent E, Narváez JA, et al. Usefulness of magnetic resonance imaging of the hand versus anticyclic citrullinated peptide antibody testing to confirm the diagnosis of clinically suspected early rheumatoid arthritis in the absence of rheumatoid factor and radiographic erosions. Semin Arthritis Rheum. 2008;38(2):101-109. doi:10.1016/j.semarthrit.2007.10.012

35. Buisman LR, Luime JJ, Oppe M, Hazes JMW, Rutten-van Molken MP. A five-year model to assess the early cost-effectiveness of new diagnostic tests in the early diagnosis of rheumatoid arthritis. Arthritis Res Ther. 2016;18(1):135. doi:10.1186/s13075-016-1020-3 


\section{Publish your work in this journal}

ClinicoEconomics and Outcomes Research is an international, peerreviewed open-access journal focusing on Health Technology Assessment, Pharmacoeconomics and Outcomes Research in the areas of diagnosis, medical devices, and clinical, surgical and pharmacological intervention. The economic impact of health policy and health systems organization also constitute important areas of coverage. The manuscript management system is completely online and includes a very quick and fair peer-review system, which is all easy to use. Visit http://www.dovepress.com/testimonials.php to read real quotes from published authors.

Submit your manuscript here: https://www.dovepress.com/clinicoeconomics-and-outcomes-research-journal 